\title{
Research on the Integrated Development Path of Rural Culture and Tourism Industry in Shandong Province Under the Situation of COVID-19 Prevention and Control
}

\author{
Ping Yang ${ }^{1} \&$ Fuchang $\mathrm{Yu}^{2}$ \\ ${ }^{1}$ School of Management, Shandong Women's University, Jinan, China \\ ${ }^{2}$ Shandong Agricultural Ecology and Resource Protection Station, Jinan, China \\ Correspondence: Ping Yang, School of Management, Shandong Women's University, Jinan 250300, Shandong, \\ China.E-mail: yu2568@yeah.net
}

Received: February 1, 2022

Accepted: February 25, 2022

Online Published: February 27, 2022

doi:10.20849/ajsss.v7i2.1012

URL: https://doi.org/10.20849/ajsss.v7i2.1012

\begin{abstract}
Since the beginning of 2020, the sudden OUTBREAK of COVID-19 has pushed the "pause button" on the previously hot Chinese New Year culture and tourism market. On April 17, the Political Bureau of the CPC Central Committee held a meeting to study and make arrangements for regular epidemic prevention and control. The meeting stressed the need to actively expand domestic demand, release consumption potential, resume work and production, business and market, expand household consumption and appropriately increase public consumption. Expanding domestic demand has become an important way to stabilize the economy in the fight against the epidemic. As an important means to expand domestic demand, cultural and tourism consumption has the characteristics of multi-level and diversified, but also has the role of rapid market recovery and boost confidence. As an important part of the cultural and tourism industry, accelerating the revitalization and development of the rural cultural and tourism industry under the premise of normalizing epidemic prevention and control in China can not only effectively support the implementation of the rural revitalization strategy of our province, but also implement the central government's "six guarantees" policy. Based on su place in Shanghai town JiaoZhuang Village, zaozhuang taierzhuang Pi town of surging waves temple village zhuang town, heze peony district Ma Ling hills, jose litsun, zibo boshan area ChiShang Town hao in the valley village, flourish NingJin street east to disappear island village five outstanding characteristics such as dependence on rural village as the breakthrough point, the tour industry of typical focus respectively in the new development under the influence of the outbreak, By means of questionnaires and depth interviews and other forms to explore the epidemic situation under the influence of each country, the existing problems in the development of tour industry integration and the prevention and control under the new normal subsequent development plan, and on the basis of exploring the suitable for our province rural epidemic prevention and control under the new normal text brigade industrial convergence development quality, and the synergistic path, find out the corresponding countermeasure, for the implementation of the strategy of rejuvenating our province rural, Crack rural development insufficient stamina also has practical significance.
\end{abstract}

Keywords: COVID-19 prevention and control, rural, wen tour industry

\section{Introduction}

The integrated development of rural culture and tourism industry is studied in the context of the implementation of the national "rural revitalization" strategy under the new normal of epidemic prevention and control. It is an inevitable requirement for realizing the beautiful vision of "seeing mountains, seeing rivers, and living nostalgia", and an important means to expand consumption, ensure employment, and increase farmers' income. This paper takes five typical villages with prominent characteristics in Shandong province that rely on rural cultural and tourism industry as the starting point, focuses on their development status under the influence of COVID-19, and explores ways to improve the quality and efficiency of the integrated development of rural cultural and tourism industry suitable for the new normal of epidemic prevention and control in Shandong Province, and finds out corresponding countermeasures for reference. 


\section{General Characteristics of Rural Cultural and Tourism Industry Development Under the Situation of Normalized Epidemic Prevention and Control}

Rural travel industry is a product of the rural social and economic development to a certain stage, is the experience of a new tourism mode, mainly is the natural ecology, rural landscape, folk custom relics, cultural scene as the carrier, to farmers as the main body in the business, its urban residents as the main target groups, in order to meet the city people enjoy the pastoral scenery, return to the simple folk vision features, At present, it has become a popular leisure holiday activity among the general public, especially urban residents. The rise and development of rural tourism has very important practical significance to close industrial relations between urban and rural areas, increase farmers' income, solve rural labor employment, improve rural infrastructure and so on. It is an effective way to promote the construction of new socialist countryside and an important means to increase village collective income.

In recent years, rural tourism in Shandong province has blossomed everywhere, and a large number of successful cases have emerged. The five village-level cases we selected are typical representatives, and their development trajectory reflects some common characteristics.

\subsection{Change Thought Understanding, Break Thought Shackle}

Through the land survey of several villages, no matter it is plain village, mountain village or coastal fishing village, the villagers were poor and the village was also poor. As a Chinese saying goes, "poverty leads to change, and change leads to success." People are the most active and important factor in productive forces, and their thoughts determine all their actions and behaviors. As long as the people want to develop and are willing to develop, there are always more ways than difficulties, and we are sure to find a good way for local development. If we shackle our minds to the days of "facing the loess and turning our backs to the sky", and fear difficulties and worry about development, even if we cling to mountains of gold and silver, we will not achieve major development and enable the people to live a better life. Just as the Chinese saying goes, "Helping the poor first", development requires changing people's thinking and understanding. The successful experience of these villages tells us that as long as we have a good understanding of the situation and a strong desire for change and development, our hearts will be in the same place and our strength will be in the same place. Even if we encounter difficulties and obstacles in development, it will be relatively easy to overcome and succeed.

\subsection{Dig Resource Endowment Deeply and Highlight Local Characteristics}

Investigation of this a few village, development relied on the local characteristic of the resources endowment, such as hao in the valley village by green water castle peak, Chen Zhuang village by mulberry tree in one hundred, jose litsun by apple and the five fuwa, east to disappear island village by fishery cultivation, temple village, blue waves by the home stay facility, these natural endowment, why not developed in the past? First, the concept has not kept up with the development trend, do not pay attention to the rise of rural tourism, do not understand. Second, they do not regard these resource endowments as treasures. They are used to looking at mountains, rivers, trees and houses. They do not dig deep into the development opportunities hidden behind mountains, rivers, trees and houses and beg for food with a golden bowl. Therefore, in pursuing development, local resources must be fully utilized. To make full use of local resources, we need to find the right entry point and growth point for development. Living means "relying on mountains and relying on water" and making the best use of the advantages of characteristic resources. The successful experience of these villages tells us that development should be based on in-depth investigation and research, in accordance with local industrial policies and development plans, taking into full consideration the resource endowment, industrial base, traditional habits and other factors of the villages, and developing according to local conditions and village conditions.

\subsection{Follow the Development Trend and Continue to Explore and Innovate}

At present, tourism, including rural tourism, develops rapidly, and the homogenization phenomenon is serious. How to stand out in the fierce market competition is a major issue in front of development. Several villages in the survey gave good answers in this respect. For example, hao Yu village from the development of a single farmhouse to the company operation, and then to the national joint-stock system; Muli Village has developed from apple picking to folk tourism of dough figurines and then to ecological tourism. The development of these villages not only dare to take the first step, but also good at grasping the development trend and trend, trying to innovate again and again, step by step forward. If we stay in the primary stage of simply doing "farm music", "fishing music", "picking tour" and so on, we can not give new content and inject new elements according to the development of the market. Even if the initial stage of development may be prosperous for a while, it will certainly not be prosperous for a long time and will be eliminated sooner or later. Village of this a few successful experience tells us that if we want to win in the fierce market competition, sanfeng development tide, must want 
to have "moved on", closely follow the development of the new situation and new demand of tourists, actively explore, bold attempt, one step at a time to go forward, to ensure that people do not always I have, people have my superior, I.

\section{Problems Existing in the Development of Rural Cultural and Tourism Industry Under the Situation of Normalized Epidemic Prevention and Control}

Several years after the outbreak of the epidemic, the cultural and tourism industry in rural Areas of Shandong province has been developing day by day through measures such as government leadership, planning guidance and financial subsidies. However, it may not be the ideal rural appearance in our eyes. Compared with advanced areas, there is still a large gap, which restricts the play of comprehensive benefits.

\subsection{The Product Grade Is Low}

Part of the rural tourism projects lack of prophase overall planning, lead to project function is too simple, combined with the construction level is low, there is no technical guidance, product stay in ornamental, picking taste, rural labor experience such as low level, and tourists expect to participate in the shopping, spa, resort will guide more strengths to whole construction machinery such as demand gap is very large. In recent years, as a form of tourism, home stay is booming in China. At present, Moganshan, Deqing County, Zhejiang province, has gathered more than $550 \mathrm{~b} \& \mathrm{Bs}$, including 56 boutique b\&Bs. Today, five-star hotels in many cities sell for less than 1,500 yuan a night, but it is hard to get a room in peak season. In 2016 alone, the annual revenue of 120 rooms in Moganshan Naked Heart Valley reached 200 million yuan, almost equivalent to the revenue of two five-star hotels. Many "xiaozi" people in neighboring cities, especially Shanghai, have taken going to naked Heart Valley as a symbol of life quality. On the other hand, the development of homestay in our province is still in its infancy. There are only 8 and 39 four-star and five-star homestays respectively, with the highest price of only 1000 yuan, which reflects that there is still a lot of room for improvement of high-end rural tourism products in our province.

\subsection{The Rural Tourism Brand Is Not Popular}

On the one hand, most rural tourism projects are in a state of natural development, lack of brand awareness and brand building; On the other hand, the lack of professionals, product design, promotion and customer service and other professional relatively strong work no one can do, no one can do. Our province zibo in hao yu village, binzhou west paper village, Jining shangjiu mountain village although in the vicinity of a small famous, but look across the province to see the stars without the moon, mountains without peaks, the lack of top, high-end, well-known, in the country called the rural tourism brand.

\subsection{Land Funds Restrict Development}

Although the state issued a number of documents to encourage the use of the "four wastelands" for tourism development and construction, most places use the "four wastelands" to replace farmland, resulting in no "land" available for rural tourism development. It takes about 20 million yuan to build a rural tourism destination with diversified forms of business. It is difficult to build high-quality tourism spots only by farmers themselves, and government guidance and private capital investment are insufficient.

\subsection{The Supporting Facilities and Services Are Not Perfect}

Infrastructure construction of roads, parking lots and underground pipe networks in some rural tourist spots lags behind. At the same time, the farmers' free and unrestrained habits, weak service consciousness and low cultural quality, as well as some inherent diet and health habits, directly affect the level of tourism reception service and the image of the project.

\section{The Integrated Development Path of Rural Culture and Tourism Industry in Shandong Province}

To take the road of integrated development of rural culture and tourism industry, the village collective must put the optimized development of the quasi tourism industry in the context of The Times, play the role of "new driving force", especially in the basic concept of fundamental change, based on local resources and environment, according to local conditions, to achieve sustainable development.

\subsection{Featured Industries Are an Important Support for Rural Tourism Development}

Based on the existing characteristics of rural industries, and to expand and extend these industries, make it become a solid foundation for the development of rural tourism. On the basis of these characteristic industries, rural tourism products such as leisure agriculture, natural education, deep processing of agricultural products, handicraft production, local cuisine, shopping and rural vacation will be developed to enrich new forms of business and expand the connotation and extension of rural tourism. 


\subsection{Industrial Integration Is the Best Choice for Rural Tourism}

Rural tourism development, route choice is crucial, must firmly grasp the industrial integration development, highlight the link role of tourism industry, fully tap potential local products, folk customs, festivals, such as national resources, at the same time of creating outstanding features of tourism products, efforts to promote production barrage, realize industrial chain addition, multiplied by the value chain, supply chain is same.

\subsection{All-for-one Tourism Is an Effective Way to Develop Village Tourism}

The whole region tourism is a new concept of developing regional tourism resources comprehensively, which is to position and construct an administrative region as a tourist area. Holistic tourism, which emphasizes the concept of panorama, is inseparable from the good landscape corridors and ecological environment of the whole region. It not only involves the tourism industry itself, but also other related industries. Through the building of regional brands and the development of featured products, the quality of rural tourism can be finally improved.

\subsection{Spatial Cognitive Transformation Is a New Perspective of Rural Tourism Development}

Rural tourism should be given a new meaning and space. General Secretary Xi mentioned that "seeing mountains, seeing water, remembering nostalgia" is the spatial element of the countryside. Only by changing the spatial cognition of rural tourism, realizing the transformation from rural construction to rural development, paying more attention to its pleasure value and social healing value in the process of social development, and giving it more possibilities of innovation, can rural tourism jump out of the traditional dependence on agricultural resources and move towards a broader world.

\subsection{Homestay Operation Is the Natural Regression of Rural Tourism Development}

Homestay is the best place to experience the scenery, feeling, atmosphere and taste of the countryside. From the farmhouse to the current 3.0 era of home stay, is a qualitative leap in rural tourism. In the ideal sense, homestay not only has the function of accommodation, but also should highlight the cultural connotation of the place of accommodation. At present, homestay, especially higher-grade homestay, focuses on finding traditional culture, historical culture, regional culture and national culture from homestay. The leverage of the consumer market shows that the more rich cultural characteristics of the home stay more favored by tourists. This is not only the manifestation of cultural confidence, but also the return of tourism industry confidence.

\section{References}

Ba, D.-X. (2018). 40 years of Reform and opening up: Value and Trend of Integrated development of Chinese culture and tourism. Gansu Social Sciences, (5), 105-108.

Cai, X.-L., \& Yu, H. (2019). Research on tourism innovation and transformation of ethnic traditional cultural resources from the perspective of rural revitalization. Rural Economy, (5), 17-21.

Meng, M.-Q. (2017). Analysis on the Integration development of Cultural Industry and Tourism Industry. Zhongzhou Academic Journal, (11), 65-68.

Tang, J. (2018). The Characteristic cultural Path of implementing rural revitalization Strategy in western China -An empirical analysis based on Sichuan Province. East China Economic Management, (11), 223-224.

Yu, L. (2019). Development logic, obstacles and Path selection of Rural tourism in Jilin Province under rural revitalization Strategy. Journal of Yanbian University (Social Science Edition). (4), 38-43.

Zhang, T. (2018). Cultural creativity boosts the transformation and upgrading of rural tourism in the new era. Tourism Tribune, (7), 152-156.

Zhou, C.-B. (2018). Dynamic Mechanism and Synergistic Effect of cultural and tourism industry integration. Social Scientist, (2), 58-61.

Zhou, C.-B. (2018). Integration of Cultural Industry and tourism Industry: Theory and Empirical Evidence. Enterprise Economy, (8), 112-116.

\section{Copyrights}

Copyright for this article is retained by the author(s), with first publication rights granted to the journal.

This is an open-access article distributed under the terms and conditions of the Creative Commons Attribution license (http://creativecommons.org/licenses/by/4.0/). 